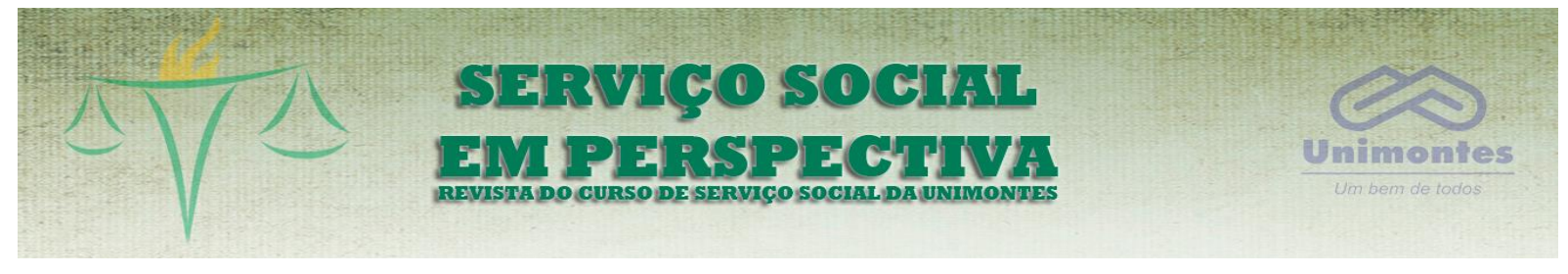

\title{
AS CONTRIBUIÇÕES DA COORDENAÇÃO DE ESTÁGIO PARA A QUALIFICAÇÃO DA SUPERVISÃO EM SERVIÇO SOCIAL
}

\section{THE INTERNSHIP COORDINATION CONTRIBUTIONS FOR THE SOCIAL WORK SUPERVISION IMPROVEMENT}

\author{
Júlia Aparecia Soares de Paula ${ }^{1}$ \\ Paula dos Santos Kropf ${ }^{2}$
}

Resumo: O presente artigo apresenta um debate construído centrado na compreensão acerca da Coordenação de Estágio como um agente de potencialização da articulação dos sujeitos envolvidos na supervisão e no processo de formação em Serviço Social. O objetivo desta proposta é o de contribuir com a discussão a respeito das ações para a experiência do estágio na contemporaneidade, na busca de construção de vivências qualificadas para a formação profissional. Para isso, na pesquisa se recorre se recorreu às fontes bibliográficas e documentais, à sistematização das ações e pesquisas realizadas, bem como à experiência profissional como docentes da disciplina de supervisão acadêmica e à frente da gestão, desde agosto de 2019, da Coordenação de Estágio da Escola de Serviço Social da Universidade Federal Fluminense, em Niterói. As reflexões estão organizadas a partir da apresentação da histórica construção das conquistas da categoria na valorização do estágio para a formação, e elenca alguns desafios enfrentados por estudantes e profissionais supervisores - acadêmicos e de campo, gestores e técnicos assistentes sociais. Finalizando, realiza a análise de ações que podem nortear a intervenção para qualificar a gestão e, consequentemente, a experiência da supervisão de estagiários nos espaços de formação. Nesse sentido, incita um diálogo a partir do entendimento de que uma perspectiva crítica deve ser capaz de estimular uma reflexão teórica dos papeis de cada sujeito no processo de estágio, possibilitando estratégias de enfrentamento

\footnotetext{
${ }^{1}$ Assistente Social. Graduação, Mestrado e Doutorado em Serviço Social pela Universidade Federal do Rio de Janeiro. Professora da Escola de Serviço Social da Universidade Federal Fluminense (UFF/Niterói). Coordenadora de Estágio e do Grupo de Estudo e Pesquisa Trabalho e Sociabilidade na Contemporaneidade (GETSC). E-mail: depaula.julia@yahoo.com.br

${ }^{2}$ Assistente Social. Graduação, Mestrado e Doutorado em Serviço Social pela Universidade Federal do Rio de Janeiro. Professora da Escola de Serviço Social da Universidade Federal Fluminense (UFF/Niterói). Vice-Coordenadora de Estágio e coordenadora do Grupo de Estudo e Pesquisa Cultura na Sociabilidade Contemporânea. E-mail: paulakropf@gmail.com
} 
consistentes e novas proposições para transformar a realidade da formação profissional.

Palavras-chave: Estágio supervisionado; Serviço Social; Coordenação de Estágio; Política Nacional de Estágio.

\begin{abstract}
The paper discusses about the internship coordination as an agent to strengthen the articulation of the subjects involved in the supervision and training process in Social Work. As a methodological choices, it been used bibliographic and documentary sources, as well as the systematization of professional experience in front of the UFA internship coordination management, since August 2019. The ideas are organised from the historical construction of the achievements of the category, regarding to the valorization of the internship for training and lists some challenges faced by students and professional academic and field supervisors, managers and social workers. Finally, in order to contribute to an analysis of actions that can guide an intervention to improve a management and, consequently, the experience of supervising. In this sense, inciting a dialogue from the understanding of a critical perspective must be able to stimulate a theoretical reflection of the roles of each subject in the internship process, which allows for consistent coping strategies and new proposals to transform the reality of professional training.
\end{abstract}

Keywords: Supervised internship; Social service; Internship coordination; Internship National Politic.

\title{
ESTÁGIO EM SERVIÇO SOCIAL: POR ONDE COMEÇAR A PENSAR?
}

A escrita de um artigo pressupõe a exposição de um raciocínio construído por meio do desenvolvimento de ideias, articulação de saberes e vínculo com os desafios postos pela realidade. Tais saberes, além daqueles em elaboração, também correspondem ao que anteriormente foi produzido nas distintas áreas de conhecimento correlatas, sendo fruto das ações e trajetórias historicamente percorridas pelos sujeitos coletivamente antes do presente.

Por esse caminho, pensamos que, para falar sobre a experiência atual da supervisão e suas possibilidades no tocante ao lugar da Coordenação de Estágio, é indispensável elucidar alguns pontos de partida. $O$ primeiro deles pode ser provocado pela afirmação de Guerra (apud LEWGOY, 2010, p. 45) de que "[...] só o estágio permite a análise concreta de situações concretas". Este fio será retomado 
em alguns momentos da exposição, ajudando a concatenar algumas reflexões sobre esse espaço fundamental do processo de formação profissional.

Como parte importante de compreensão da supervisão de estágio em Serviço Social, está sua história e seu significado ao longo da formação profissional. A análise do desenvolvimento atual do debate é resultado da construção enquanto categoria desde os primórdios, com a existência das primeiras escolas e as reflexões a respeito da condução no processo educacional. Os desafios pedagógicos hoje, também resultam de um enfrentamento ao conservadorismo e o tecnicismo empregado na experiências do ensino e aprendizagem e nas formas de supervisão de estágio, na busca por avançar constantemente na construção de uma formação de qualidade, sem perder de vista a natureza interventiva do Serviço Social.

Enquanto reflexão, cabe localizar histórica, política, econômica e culturalmente, a realidade da qual falamos. Nesse sentido, a sistematização da experiência profissional parte de vivência como docentes da disciplina de supervisão acadêmica e, atualmente, à frente da gestão ${ }^{3}$ na Coordenação de Estágio da Escola de Serviço Social, da Universidade Federal Fluminense (ESS/Niterói). Entende-se que o momento é marcado pelo acirramento da disputa em torno da busca pela educação pública, laica e de qualidade contra o corte de verbas, a precarização das condições de trabalho e do acesso ao direito à educação, avançando na decadência do discurso elitista e o conservador, que tem ganhado cada vez mais espaço no Governo de Jair Bolsonaro. Destaca-se, portanto, a reconfiguração do Estado diante da crise capitalista, as formas regressivas de respostas às expressões da questão social e os impactos para o trabalho profissional.

Docentes e estudantes se colocam na defesa de uma educação de qualidade e dos valores em consonância ao projeto ético-político do Serviço Social, na busca de uma razão crítica e comprometida, da função pública e coletiva do acesso aos direitos, participando da construção de respostas para a superação dessa sociedade tão desigual. Mas há, portanto, grandes desafios para a garantir a formação de

\footnotetext{
${ }^{3}$ Gestão iniciada em agosto de 2019 e com duração de quatro anos, tendo o seu término previsto para 2023.
} 
assistentes sociais comprometidos com um projeto profissional que se contrapõe a qualquer forma de injustiça, na defesa da liberdade, igualdade, ampliação e consolidação da cidadania, equidade e justiça social, eliminação de todas as formas de preconceito, dentre outros princípios norteadores da profissão. No bojo deste agravamento da experiência da vida social na atualidade, está constituído o terreno para os primeiros contatos com a prática profissional para estudantes ao fazerem parte dos espaços socio ocupacionais através do estágio.

Afinal, estágio e supervisão, como elementos inerentes da formação e exercício profissional, sofrem conjuntamente os reflexos da crise do capital, da política reducionista de direitos sociais efetuada pelo Estado, da reforma universitária, da mercantilização da educação, dos achatamentos salariais, do retrocesso ao pensamento conservador e suas sequelas desenfreadas. (CAPUTI, 2016, p. 391)

No que se refere às especificidades desta etapa do processo formativo, identifica-se o impacto na intensificação da precarização das condições de vida dos estagiários, fazendo com que muitos tenham que dividir seu tempo de estudo e atividades no campo com as disciplinas, trabalho, fazeres domiciliares, busca por sobrevivência e conclusão do curso, como demonstrado na pesquisa realizada pelas assistentes sociais da Coordenação de Estágio (SILVA; COIMBRA, 2019). Mas, também, a complexa realidade vivenciada pelos assistentes sociais em seus espaços sócio-ocupacionais, tendo que lidar com demandas institucionais, dos usuários e lutar por melhores condições de trabalho, sendo agente de formação, por meio da supervisão direta dos estudantes. O que demonstra a impossibilidade de pensar o estágio supervisionado, sem considerar a indissociabilidade entre trabalho e formação profissional, como no argumento de Ferri (2020).

Desta forma, parte-se da defesa de que a supervisão direta envolve três sujeitos - estudante, supervisor de campo e supervisor acadêmico - que possuem diferentes atribuições. Estes devem, de modo geral, assegurar que a supervisão ocorra de forma concomitante e que a inserção do estudante no espaço socio ocupacional ocorra preconizando o entendimento de que é uma atividade integrante da formação profissional, portanto, de ensino e aprendizagem. Mas destacamos que, nesta construção, também estão elencadas na Política Nacional de Estágio 
(PNE), as atribuições da Coordenação de Estágio, entendida como "esfera de organização e gestão da política de estágio" (ABEPSS, 2010, p. 24) e trazemos para o debate a oportunidade, nesse espaço, de realizar atividades conjuntas com os diferentes sujeitos, como estratégias de fortalecimento e qualificação da supervisão de estágio em Serviço Social.

Assim, a partir da apropriação de autores reconhecidos pela temática, documentos produzidos pela categoria profissional, pela Coordenação de Estágio da ESS/Niterói e, na participação em espaços de troca com outras UFAs e, com entidades da categoria profissional, como encontros da ABEPSS e da Comissão e Formação do CRESS/RJ, é realizada a reflexão a respeito da intervenção profissional para qualificação da formação frente às demandas colocadas pelo estágio supervisionado. Entendemos as ações aqui apresentadas como potencializadoras para a articulação dos sujeitos, abarcando possibilidades de atuação profissional no âmbito da gestão para a implementação da Política Nacional de Estágio, sem a pretensão de esgotar o debate no espaço educacional.

\section{BREVE CONTEXTUALIZAÇÃO DO ESTÁGIO EM SERVIÇO SOCIAL - HISTÓRIA E SIGNIFICADO}

Falar sobre a supervisão em sua dimensão histórica faz remissão ao fato de que esta é, segundo Lewgoy (2010), uma das ações mais antigas concernentes ao processo de ensino e aprendizagem, em termos gerais, com registros de ocorrência desde a Grécia Antiga. Com relação ao Serviço Social, inicialmente, esta surge como um processo de treinamento para execução das ações de caridade no sentido de alinhá-los às instituições provedoras. Antes de sua profissionalização, a supervisão estava mais vinculada ao campo do trabalho e o estágio, por sua vez, entendido como um treinamento vocacional, distante de qualquer perspectiva de articulação com um sentido formativo. Além disso, havia também a percepção de que o estágio proporcionava o aprendizado de fato, pois oportunizava a experiência na prática. Neste momento, o supervisor desempenhava função "de natureza mais administrativa do que pedagógica". 
Somente na segunda década do século XX onde, dentre as influências se destaca a obra de Mary Richmond, O Diagnóstico Social, é que o processo de supervisão vai absorver uma aproximação com o ensino, tomando aquele como um "orientador da metodologia". É procedente observar que, aqui, assim como a profissão atendia às exigências socialmente colocadas, especialmente vinculadas ao impulso modernizador - de urbanização e industrialização - também a supervisão deveria corresponder às insígnias daquele tempo. Não havia ainda um posicionamento de contestação da ordem vigente e tampouco das requisições dela decorrentes.

No Brasil, com o surgimento das primeiras escolas de Serviço Social em diante, situada em meados da década de 30 , aos poucos a formação profissional vai se constituindo como parte, e se desdobra em processos de aprendizagem diversos. Estes acompanham o cenário social, em que as transformações do Estado de modo a atender à promessa de crescimento incutida no projeto desenvolvimentista passam a exigir maior qualificação dos profissionais, no sentido de adequação às mudanças em curso. Assim, corroborando para a elevação do Serviço Social a um patamar de institucionalidade, se distanciando, em parte, de sua vinculação inicial à religião. Neste período, se registra uma maior aproximação às influências do Serviço Social norte-americano.

Com o Movimento de Reconceituação temos um intenso processo de mudanças no que tange à profissão e seus elementos norteadores, cuja perspectiva de busca por uma ruptura e refutação ao Serviço Social tradicional adquire destaque. Entretanto, segundo Lewgoy (2010), a renovação demandou grande esforço de construir novas bases para o estatuto da profissão. Este notadamente promoveu avanços no campo teórico, contudo, análises posteriores indicam que naquele momento ficou faltando maior atenção à ação profissional e, consequentemente, também à supervisão.

Os próximos passos da trilha no sentido da recusa do projeto modernizador que se colocava no período, foram amplamente descritos e difundidos por grandes obras de referência da área. De modo geral, as mudanças, ao adquirirem fôlego, vão paulatinamente contemplando o Serviço Social em sua totalidade - da expansão de uma produção teórica, ao início e subsequente ampliação dos cursos de pós- 
graduação, à reformulação do currículo e do código de ética, passando pela expressiva organização da categoria ao longo da década de 1980. Todo esse impulso de negação das bases tradicionais da profissão, somadas à elaboração de uma leitura crítica da realidade, vão atingir sua maturidade, segundo Netto (2006), nos anos 1990.

A complexa relação de construção e efetivação no cotidiano, por parte da categoria, de um projeto profissional contra hegemônico, coloca o desafio de que a materialidade palpável não se dá transmutada em um documento específico, uma cartilha de como fazer, nem com a repetição de frases que definam os princípios e valores da profissão. O projeto profissional, em sua definição, segundo Netto (2006, p. 4), é de âmbito coletivo e

envolve uma série de componentes distintos: uma imagem ideal da profissão, os valores que a legitimam, sua função social e seus objetivos, conhecimentos teóricos, saberes interventivos, normas, práticas etc. São várias, portanto, as dimensões de um projeto profissional, que deve articulálas coerentemente.

Se observa, portanto, não se tratar de algo como uma carta de recomendações, mas, de um conjunto de elementos que indicam certa projeção coletiva do Serviço Social sobre sua constituição e efetivação socialmente. Entretanto, seu processo de consolidação é marcado pela existência dos documentos estruturantes, ainda que neles não se esgote. Assim, as bases normativas são representadas no Código de Ética e a Lei de Regulamentação da profissão (Lei n. 8.662, de 7 de junho), ambos de 1993, e as Diretrizes Curriculares para o curso de Serviço Social, da ABEPSS, de 1996. É a partir de seus eixos fundamentais que trataremos a seguir sobre o lugar do estágio na formação profissional e o papel e relevância da supervisão, pontuando os marcos expressivos.

Nos interessa aqui destacar que, de modo geral, estes marcos normativos expressam o acúmulo que a profissão realiza durante as décadas de 1970 e 1980 e estão alinhados a uma interpretação crítica da realidade, de negação da lógica capitalista, e defesa de uma sociedade mais justa, igualitária e emancipada. Valores esses que vão permear e provocar alterações em muitos aspectos relacionados à 
profissão - aqui nos concentraremos com mais ênfase na formação profissional e, especialmente, na questão da supervisão de estágio.

Para isso, parece procedente avançarmos para as contribuições das Diretrizes Curriculares da ABEPSS (1996), como um marco da orientação para a formação em Serviço Social, trazendo novos elementos para pensar na formação a partir da necessária relação ética, teórica e prática. No referido documento, é válido ressaltar, primeiramente, que fica explícito em que bases se fundamentam 0 profissional que o Serviço Social pretende formar, em consonância com os princípios do Código de Ética da profissão. A formação está orientada então no sentido de promover o requisito para a prática profissional de aprofundado conhecimento crítico sobre a realidade social, considerando as particularidades da formação socio histórica do Brasil, sob a perspectiva da totalidade. Assim, garantindo condições de que o exercício profissional esteja pautado pela indissociabilidade das dimensões constitutivas de sua prática: técnico-operativa, teórico-metodológica e ético-política.

O estágio está presente nas Diretrizes Curriculares como atividade indispensável integradora do currículo, tendo assegurada a imprescindibilidade da supervisão em seus princípios, a partir da "Indissociabilidade entre estágio e supervisão acadêmica e profissional" (ABEPSS, 1996, p. 7). Segue abaixo a definição de estágio supervisionado contida no documento:

\footnotetext{
Estágio Supervisionado: É uma atividade curricular obrigatória que se configura a partir da inserção do aluno no espaço sócio-institucional objetivando capacitá-lo para o exercício do trabalho profissional, o que pressupõe supervisão sistemática. Esta supervisão será feita pelo professor supervisor e pelo profissional do campo, através da reflexão, acompanhamento e sistematização com base em planos de estágio, elaborados em conjunto entre Unidade de Ensino e Unidade Campo de Estágio, tendo como referência a Lei 8662/93 (Lei de Regulamentação da Profissão) e o Código de Ética do Profissional (1993). O Estágio Supervisionado é concomitante ao período letivo escolar. (ABEPSS, 1996, p. 19)
}

Não são poucos os desafios para a materialização no cotidiano de formação e prática profissional sintonizadas com o projeto ético-político, e estes em geral perpassam a superação de experiências vinculadas ao exercício profissional cujos aspectos centrais do Serviço Social tradicional - a herança do conservadorismo, o pragmatismo e a ideia de uma neutralidade - ainda ressoem. Nesse sentido, pode- 
se afirmar que não é possível realizar um debate da supervisão em serviço social, sem destacar a articulação necessária entre conhecimentos acadêmicos e a orientação profissional no campo. Como defendido por Ferri (2020, p. 234):

entende-se que o estágio é o espaço privilegiado da formação profissional e deve ocupar lugar de destaque na formação por ter a profissão uma natureza interventiva, tem as condições de propiciar a síntese entre o trabalho e a formação profissional, mas as condições de realização da supervisão dependem das condições de realização do trabalho profissional e das condições sob as quais a formação se realiza.

O reconhecimento de que esta realidade requer estratégias e respostas profissionais que ampliem a identificação da legitimidade da perspectiva crítica, faz com que este movimento se traduza em sistematizações teóricas e normativas. É neste sentido que, em 2010, após um longo empreendimento de mobilização, debates e construção coletiva da categoria, é publicada a Política Nacional de Estágio (PNE), pela ABEPSS.

\section{COORDENAÇÃO DE ESTÁGIO: LIMITES E POSSIBILIDADES DE AÇÃO}

É importante assinalar o traço paradoxal que marca a trajetória da profissão, propriamente nos idos subsequentes aos anos 1990 e o amadurecimento do projeto ético-político da profissão. Enquanto o Serviço Social avança no campo teórico e na elaboração de parâmetros normativos que contribuíssem para a construção de um direcionamento que legitimasse os princípios do projeto profissional, o contexto social é de retrocessos se olharmos pela perspectiva dos direitos sociais.

O agravamento das mudanças no mundo do trabalho, os impactos da retração crescente do Estado, incidem diretamente nas condições de vida dos indivíduos sociais. Ao mesmo tempo que estimulam o enfrentamento da desigualdade social em suas múltiplas manifestações, a busca de estratégias cotidianas de respostas é um desafio cada vez mais acentuado. É nesse contexto que se dá o esforço coletivo de elaboração da PNE, centrada na constatação acerca da "urgência na defesa de um projeto profissional vinculado a um projeto de 
sociedade no horizonte estratégico da ampliação dos direitos, na direção da emancipação humana" (ABEPSS, 2010, p. 1).

Fatores como a precarização do ensino superior, a ampliação do ensino à distância, impactam diretamente tanto na qualidade da formação profissional quanto na realização do estágio supervisionado, o que vinha implicando em situações que apresentavam violação às recomendações expressas nas Diretrizes Curriculares. Assim, o documento está organizado de modo inicial pela contextualização do panorama social que impulsionou a mobilização da categoria profissional e seus órgãos representativos para debates e elaboração do documento; seguido pelos princípios norteadores de sua realização e da concepção de estágio supervisionado; e, por fim, das atribuições dos sujeitos e instâncias envolvidas no estágio supervisionado e as estratégias de operacionalização.

Pelos limites próprios de um artigo, colocaremos o foco sobre a questão da Coordenação de Estágio, responsável pela organização e gestão da política de estágio na Unidade de Formação em Serviço Social e, uma vez que essa coordenação não exista, caberá à Coordenação de Curso o desenvolvimento da função. Mas, defendemos que, segundo a PNE (2010), deve-se entender a valorização do estágio como processo fundamental para a qualificação da formação profissional, o que exige uma estrutura de gestão e autonomia nas decisões, organizacional e de pessoal.

Apresentada as condições básicas para que a coordenação desenvolva suas ações, há potencialidade dos sujeitos envolvidos realizarem uma intervenção capaz de qualificar a supervisão de estágio. Sendo de suma importância a contribuição que a Coordenação pode dar para a compreensão do estágio como esfera privilegiada no processo de formação, na busca por uma experiência qualificada dos estudantes e no diálogo com as assistentes sociais de campo, a respeito do avanço e concretização das conquistas históricas da profissão. Ou seja,

Compreender o significado da profissão na sociedade capitalista e a relação teoria e prática é fundamental para garantir uma formação e um exercício profissional que não reproduzam equívocos e posturas fatalistas ou messiânicos quanto às possibilidades de materialização de nosso projeto ético-político no cotidiano. A tarefa que se coloca para todos nós assistentes sociais é acionar as dimensões teórico-metodológica, técnico-operativa e 
ético-política no cotidiano da formação e trabalho profissional (FERRI, 2020, p. 237).

Desta maneira, as ações da Coordenação de Estágio são apresentadas como potencialidade para ampliar a qualificação da formação, pois dependem de um conjunto de fatores e sujeitos envolvidos na sua implementação. Dentre esses, destacam-se: autonomia para atuação, espaço físico e equipamentos - sala de atendimento; carro para visitas institucionais, telefone etc.; equipe permanente (com docente responsável, assistente social e secretaria); e a importante atuação de outros sujeitos no processo de Estágio, como a Coordenação de Curso e Departamento, Entidades Representativas da Categoria Profissional e da Formação em Serviço Social (CFESS; CRESS; ABEPSS; ENESSO); Instituições conveniadas; assistente social supervisor de campo; professores supervisores e estudantes.

Com a função de articular o processo de fortalecimento da tríade dos sujeitos envolvidos na supervisão do estágio; segundo Lewgoy (2009, p.33), constituída por supervisor pedagógico, assistente social de campo e aluno. Defendemos que a gestão da Coordenação de estágio, além da adoção de um direcionamento democrático na condução das ações, também pode e deve participar da intervenção, juntamente com os supervisores (acadêmicos e campo) que estão diretamente em contato com o estagiário, por meio de atividades que preparem a entrada no campo, contando com a participação das entidades representativas da categoria e de formação nos espaços de troca desenvolvidos, e acompanhamento do atendimento desses estudantes.

Nesse sentido, a articulação dos sujeitos responsáveis pela supervisão abarca um leque de possibilidades de atuação profissional na gestão e implementação da Política Nacional de Estágio (2010). Entretanto, mesmo que identificadas como norteadoras, essas ações não possuem a pretensão de esgotar o debate da intervenção profissional no espaço da coordenação de estágio, pois outras formas de atuação podem ser desenvolvidas, e também é necessária a compreensão de que nem todos os espaços de formação profissional possuem as mesmas condições para a implementação.

Com o entendimento de que a condição ideal é uma suposição sem fundamento para implementação das ações na realidade, cabe à gestão o papel de 
buscar o melhor resultado diante dos desafios (internos e externos) apresentados, lidando com os recursos existentes e conquistados. Em outras palavras, pensar em como a Coordenação de Estágio, diante do limite de tempo e autonomia da gestão, dos recursos físicos e humanos das universidades, pode contribuir na articulação dos sujeitos envolvidos no processo de supervisão, tendo em vista o atendimento ao objetivo de qualificação da formação.

\section{OS DESAFIOS DE GESTÃO E OPERACIONALIZAÇÃO DO ESTÁGIO}

A gestão da Coordenação de estágio, responsável pelo planejamento e implementação dos princípios e diretrizes da PNE (2010), deve buscar a articulação de profissionais, estudantes e entidades da categoria para uma participação ativa na formulação e operacionalização dos projetos, orientada pelo aprimoramento do processo de supervisão do estágio, o atendimento aos estagiários e a interação com o assistentes sociais de campo. Entretanto, muitos desafios são apresentados para a gestão, com diferentes sujeitos e necessidades colocadas, com demandas a serem solucionadas, diante de um cenário de recrudescimento dos direitos e valores democráticos.

O primeiro desafio é a própria função de planejamento, de elaborar propostas de normas e diretrizes gerais para a operacionalização da política de estágio, condizente com os critérios e objetivos para defender e assegurar uma formação profissional alicerçada na teoria social crítica, em consonância com os princípios do projeto ético-político e alinhado a um projeto societário que visa a emancipação humana. Sendo primordial realizar a gestão com a participação de docentes, discentes e supervisores de campo, num processo de democratização das decisões a respeito das atividades a serem realizadas, acompanhamento e avaliação do desenvolvimento do Estágio.

Segundo Teixeira (2009, p. 3-4), as atuais exigências de democratização do espaço público, possibilitam decisões cunhadas no âmbito da gestão e, embora entendamos essa autonomia como relativa, tende a deixar de ser cada vez mais centralizada. A dificuldade encontrada na atividade de planejar está tanto na função de direção e de organização que cabe à gestão - diante da complexa relação 
institucional, de autonomia e recursos necessários para definir ações futuras desejadas - quanto de agregar os sujeitos envolvidos para participação e responsabilização para a realização. "Cabe, entretanto, a gestores e técnicos, processar teórica, política e eticamente as demandas sociais, dando-Ihes vazão e conteúdo no processo de planejamento e gestão, orientando a sua formatação e execução.", sem perder de vista a necessidade de que sejam "materializadas por meio de um cuidadoso processo de planejamento institucional, com alcance capilar, indicando desde concepções globais até ações (na ponta), de execução de políticas públicas".

Ou seja, para a realização dos objetivos, faz-se necessário definir e detalhar o trabalho a ser realizado, etapas a serem construídas coletivamente, também devendo existir as condições para a mobilização de recursos e uma implementação participativa. Como entendido por Teixeira (2009, p.6), "o planejamento contemporâneo põe, claramente, no âmago de sua reflexão, o papel da estratégia no processo de tomada de decisões compartilhadas", sem perder de vista a necessidade de avaliações continuadas, na busca pela qualidade dos resultados das ações planejadas.

Quando tratamos, portanto, de questões como recursos e disponibilidade de tempo para participação, vê-se que o primeiro depende diretamente das condições de cada UFA e, o segundo, acaba limitado na hora da operacionalização. As precárias condições dos equipamentos, a ausência de profissionais, carros para visitas institucionais e até mesmo telefone, são alguns dos fatores que influenciam no desenvolvimento do trabalho. Mas também, as exaustivas horas em múltiplas funções, tanto do docente (sala de aula, gestão, orientações, pesquisa, extensão), quanto do assistente social de campo com diferentes vínculos de trabalho. $\mathrm{O}$ que se intensifica com as particularidades das demandas institucionais como, por exemplo, a necessidade de respostas imediatas dos usuários, e o rodízio de docentes nas disciplinas de supervisão acadêmica, dificultando o envolvimento mais contínuo com as propostas previamente planejadas.

Nesse sentido, mais do nunca, faz-se de suma importância, o fortalecimento dos espaços de debate internos e externos das UFAs junto às entidades representativas e os sujeitos diretamente envolvidos na supervisão, no intuito de 
buscar saídas coletivas para enfrentar os desafios quanto ao aperfeiçoamento da experiência do estágio. Sendo a redução do distanciamento com a instituição de estágio e assistente social supervisor de campo um importante passo nesse processo, na busca por diálogo para acompanhamento do estudante, participação nas atividades e cursos realizados pela unidade de formação.

Um outro grande desafio para a qualificação da experiência do estágio está na condição de existência vivenciada pelos estudantes, sua vida e a necessidade de recursos para permanência no curso. Ao entender essa realidade, a Coordenação de Estágio pode buscar encaminhamentos, juntamente com a Coordenação e Curso e os profissionais da gestão, para tentativa de atendimento das demandas e uma melhor experiência do estágio. Entretanto, é necessário pontuarmos que as limitações decorrentes da desigualdade inerente à lógica social vigente muitas vezes extrapolam o campo de possibilidades e recursos disponíveis, persistindo, em alguma medida, como obstáculos à plena experiência de formação.

No estágio, há a intensificação de questões como tempo e gastos, pois traz a exigência de maiores recursos para passagem e alimentação, dificultando a permanência ou disponibilidade de horário para conseguir emprego. Nesse período, há também a complexa relação de atuação conjunta com um assistente social, agregando o conhecimento de funções e ação profissional, ou seja, a entrada no campo como uma nova descoberta do fazer profissional e das possibilidades e limites da intervenção social.

A inserção no campo possibilita a conexão do que aprende em sala de aula com o processo do fazer profissional, mas pode trazer de forma mais aguçada 0 dilema das relações sociais e busca por sua transformação. Se no primeiro momento, de entrada no curso de Serviço Social, ao iniciar um processo de formação que busca desvelar a sociedade capitalista em toda sua essência, criando um pensamento contra-hegemônico, o estudante se depara com a desconstrução de toda uma vida de ações estimuladas pelas relações sociais reificadas. Esses estudantes, indivíduos reais, ao adentram na experiência do estágio, com um novo pensamento e as condições materiais (muitas vezes) parecidas com a dos usuários dos serviços, se deparam com o anseio de transformação, mas encontram o limite da intervenção para conseguir modificar essa realidade. 
Mesmo a questão não sendo individual, pois se trata de um projeto societário que nenhuma ação profissional, ou projeto de uma categoria, conseguirá enfrentar isoladamente (NETTO, 2006), o descontentamento, até com uma intervenção qualificada da profissional de campo, pode existir. Observamos nos atendimentos realizados, na coordenação de estágio, um grande número de estudantes que solicitam encaminhamento para acompanhamento psicológico, e nas disciplinas de supervisão acadêmica ${ }^{4}$, a palavra frustração ser utilizada usualmente para definição da experiência no campo.

Algumas das dificuldades apresentadas para a realização do estágio com qualidade, como o pouco tempo dedicado para as leituras e a sistematização da prática, para a elaboração de documentos como diário de campo e relatórios, são frequentes. Apresenta-se, nesse momento, a necessidade de planejamento de ações que tragam a reflexão a respeito do princípio defendido na PNE (2010), da indissociabilidade entre as dimensões constitutivas da profissão teóricometodológica, ético-política e técnico-operativa. Veja-se:

\begin{abstract}
Além dos valores ético-políticos profissionais, outros princípios devem nortear a realização do estágio no Serviço Social, na perspectiva de preservar importantes dimensões do processo formativo. Um desses princípios refere-se à indissociabilidade entre as dimensões teóricometodológica, ético-política e técnico-operativa, que deve ser garantida na experiência de estágio, evitando a tendência de autonomização da dimensão operativa em detrimento das demais, especialmente quando se trata da vivência no campo ou da supervisão de campo. (PNE, 2010)
\end{abstract}

Também cabe pensar que há uma demanda colocada ao curso, referente ao atendimento dos estudantes olhando-os em sua totalidade - condições físicas, subjetivas e sociais -, com a compreensão de que o acesso e a permanência como direito no âmbito educacional, requerem uma articulação com outras políticas sociais. Como demonstra a pesquisa realizada pelas assistentes sociais da Coordenação de Estágio da ESS/UFF - Niterói, Giselle Silva e Lenilse Coimbra

\footnotetext{
${ }^{4}$ Enquanto docentes na supervisão acadêmica, tais relatos aparecem nos espaços de discussão e reflexão em sala de aula, bem como nos registros escritos apresentados como parte da disciplina.
} 
(2019), o quantitativo de estudantes que estavam em condições curriculares ${ }^{5}$ de realização do estágio mas não ingressaram em campo e se encontravam represados no curso por esse motivo quase triplicou de 2007 até 2017, passando de 24 para 69.

O estudo foi realizado com aplicação de questionário direcionado para identificar os fatores que dificultaram o ingresso dos estudantes no estágio, obtendo 18 respostas, apresentando o perfil: "15 mulheres e 3 homens; 16 inscritos no curso - 2 com matrícula trancada; 9 empregados e 9 desempregados; 11 apresentavam disponibilidade para estágio somente nos fins de semana." (SILVA; COIMBRA, 2019, p.04). Os dados reforçam o perfil de estudantes que ingressam no curso de Serviço Social, e destacam a questão da remuneração com um fator importante para subsistência dos estudantes. Com isso, exigindo ações que respondam à necessidade de abertura de campos para atender à demanda dos estagiários trabalhadores. Com os encaminhamentos realizados pelas profissionais, a partir das situações apontadas nas respostas dos estudantes ao questionário, como abertura de novos campos e orientações para acesso às bolsas de assistência da universidade, foi identificada que a intervenção foi exitosa.

Nesse sentido, os serviços e bolsas podem ser ofertados pela universidade ou não, com acesso limitado a um pequeno número ou restrito quanto às possibilidades, se fazendo necessária a articulação intersetorial para a tentativa de atendimento das demandas. Pois, diante da necessidade de sobrevivência, da imposição de decisão sobre a disposição de dinheiro para transporte e ir à aula ou se alimentar, da incerteza quanto à procura de emprego ou realização de estágio não remunerado, a produção da vida material será a primeira opção, pois trata-se de uma significação concreta e real.

temos de começar por constatar o primeiro pressuposto de toda a existência humana, e portanto, também, de toda a história, a saber, o pressuposto de que os homens têm de estar em condições de viver para poderem "fazer

\footnotetext{
${ }^{5}$ De acordo com o currículo atualmente em vigor na ESS/UFF - Niterói, para ingressar no Estágio Supervisionado e na Supervisão Acadêmica I, o estudante deve ter cursado e obtido aprovação nas disciplinas de Ética e Serviço Social e Fundamentos Históricos e Teórico-Metodológicos do Serviço Social III, o que acontece, se cursadas regularmente, ao quinto período.
} 
história". Mas da vida fazem parte sobretudo comer e beber, habitação, vestuário e ainda algumas outras coisas. O primeiro ato histórico é, portanto, a produção dos meios para a satisfação dessas necessidade, a produção da própria vida material, e a verdade é que esse é um ato histórico, uma condição fundamental de toda a história, que ainda hoje, tal como há milhares de anos, tem de ser realizado dia a dia, hora a hora, para ao menos manter os homens vivos. (MARX; ENGELS, 2009, p. 40)

Assim, a coordenação de estágio, deve contribuir para a qualificação de uma formação com potencial crítico, contestador e também realista, diante da condição objetiva da atividade humana e dos limites existentes. Mas também, atuar para que o acesso e permanência com qualidade na política educacional, mesmo diante das condições precárias de existência, o desemprego estrutural e a refração das políticas sociais, sejam possíveis. O que reforça a urgência de aproximação com o campo de estágio, de articulação para o acesso dos estudantes à rede de serviços, da busca por ampliação de estágios com bolsas e horários possíveis de conciliar com o emprego.

Importante dizer que as questões apresentadas se referem ao estágio obrigatório e não obrigatório, talvez vivenciada de forma diferenciada pelos estudantes, podendo o estagiário ter bolsa no segundo caso, mas enfrentando outras dificuldades, como a de ser considerado mão de obra a baixo custo. Por isso, sublinhamos a necessidade de compreensão do estagiário como estudante em formação, e mesmo tendo cumprido o estágio curricular obrigatório, deve ser acompanhado pela Coordenação de Estágio e inserido na disciplina de supervisão acadêmica. Assim, o estágio supervisionado, nas modalidades obrigatório e não obrigatório, deve ser compreendido em seu processo didático-pedagógico consubstanciado pela "indissociabilidade entre estágio e supervisão acadêmica e profissional" (ABESS-CEDEPSS, 1997, p.62).

Destaca-se, portanto, que são grandes os obstáculos diante das demandas e dos recursos existentes, mas todo processo de transformação da realidade exige novas formas de intervenção e, no Serviço Social, podemos identificar um movimento constate de busca por saídas coletivas para os desafios impostos à formação e o fazer profissional. Em relação ao trabalho atualmente realizado, algumas ações estão se mostrando profícuas e o debate a seguir visa contribuir com a reflexão a respeito da potencialidade do trabalho da Coordenação de Estágio para 
o desenvolvimento da qualificação da experiência do estágio para os estudantes em formação.

\section{AÇÕES PARA QUALIFICAÇÃO DA SUPERVISÃO}

O processo de supervisão de estágio é uma tarefa que, dentre as inúmeras atribuições da Coordenação de Estágio, de acordo com a PNE, não é estritamente uma responsabilidade desta, pois deve atuar "diretamente articulada às coordenações de curso ou departamentos, de modo a viabilizar as novas demandas de qualificação do Estágio como elemento central da formação profissional" (ABEPSS, 2010, p. 24). Entendemos, assim, que a atribuição da gestão, se ampliada nessa reflexão, ao defendermos que há o desenvolvimento de atividades para fortalecimento da política educacional, via trabalho conjunto e intersetorial, podem se dar direcionadas para o atendimento do estudante em sua totalidade.

A defesa de atuação conjunta, para busca de estratégias no enfrentamento dos desafios elencados no ponto anterior, abarca também a relação de aproximação de diferentes sujeitos, já anteriormente mencionados, como: Estudantes; Supervisores Acadêmicos e de Campo; Entidades representativas da categoria. Pensada como uma parceria para garantir o diálogo em torno das orientações, planejamento e avaliação do desenvolvimento da supervisão, uma proposta interessante pode ser a criação coletiva de um plano de trabalho e sua implementação.

Nesse sentido, a Coordenação de Estágio, como indicado pela PNE (2010), pode criar e acompanhar a formação de uma Comissão de Estágio, composta por representantes de: supervisores(as) acadêmicos(as), supervisores(as) de campo e estagiários(as), com o objetivo de evitar centralização e propiciar a participação democrática e coletiva. A Comissão, a partir dos encontros, contribuiria para a elaboração do plano de trabalho, implementação - por meio da distribuição de tarefas para cada sujeito envolvido, ou grupos responsáveis, acompanhamento e avaliação permanentemente do processo de supervisão.

Na ESS/UFF - Niterói, há - já anteriormente ao início da presente gestão, um grupo de trabalho de estágio, e este se encontra periodicamente para discutir, 
deliberar e construir espaços de troca sobre a temática - seja por meio dos fóruns de supervisão e demais eventos que reúnam os sujeitos envolvidos em torno dos desafios concretos do estágio supervisionado. Em geral, as discussões e encaminhamentos tem desenhado positivamente as alternativas definidas, e trazido contribuições relevantes para a construção da situação do estágio na UFA. A proposta, então, é que sejam pensadas ações que contribuam para encontro e diálogo, como o Fórum de Supervisão de Estágio - que visem articular os diferentes sujeitos inseridos na construção e no acompanhamento do estágio-, oficinas e eventos comemorativos, mas também deem visibilidade a outras atividades possíveis de serem incluídas na elaboração de um plano de trabalho da Comissão de Estágio.

Entendemos que, para o desenvolvimento do processo de estágio, ao estudante se faz necessário cumprir algumas etapas de conhecimento, o que cabe aos demais sujeitos contribuírem na condução dessa jornada de aprendizados. Por isso, as ações podem ser divididas em duas etapas: preparação para entrada no campo e a permanência no estágio; contando com a participação dos diferentes sujeitos já indicados como participantes do processo. Destes, em especial os estudantes, devem tanto participar das atividades e dos processos seletivos, apresentar as demandas específicas para realização do estágio, quanto contribuir enquanto estagiários.

Algumas ações da primeira etapa, de preparação do estudante para a entrada no campo, podem ser pensadas no intuito de apresentação dos campos de estágio, política setorial e instituições conveniadas, os critérios para realização do estágio, legislação e documentos exigidos. De acordo com a experiência já vivenciada na UFA, bem como as ações planejadas para posterior realização, a indicação de duas atividades possíveis de serem promovidas pela Coordenação de Estágio. Ambas contribuem para aproximação do estudante aos campos, a socialização da experiência do estágio, e valorizam o trabalho desenvolvido por estagiários e assistentes sociais, consideradas importantes para conhecimento dos futuros ingressantes e também para manutenção de vínculo e permanência dos processos em curso. 
A primeira é a preparação de evento que vise a articulação com profissionais assistentes sociais e estagiários, para apresentação na UFA, do trabalho realizado no espaço sócio-ocupacional, contando com as supervisoras acadêmicas e os estudantes na organização e implementação. A segunda, a realização de encontro de estudantes da disciplina de Ética, para debate a respeito da supervisão de estágio, o processo de entrada no campo e as demandas que podem dificultar a fase inicial, com a participação de representantes de entidades representativas da categoria, estagiários, assistentes sociais de campo. Entendemos que, tanto a atividade de apresentação dos campos quanto a realização de seminários de experiências profissionais auxiliariam a escolha dos estudos, em relação à política setorial e à instituição, democratizariam a experiência do estágio, mas também contribuiriam para a sistematização do trabalho profissional, como recomenda a PNE (ABEPSS, 2010, p. 25).

Além dessas atividades, podemos mencionar também: a pesquisa de levantamento de perfil e demandas, para acompanhamento de estudantes que não iniciaram estágio já tendo cumprido pré-requisitos; contatos com as instituições campos de estágio e assistentes sociais, para levantamento de vagas e divulgação do processo seletivo, semestralmente, seguindo os critérios de abertura, ampliação e/ ou manutenção das vagas de estágio; acompanhamento na elaboração do Termo de Estágio; articulação institucional; análise de projeto e visita institucional para abertura oficial do campo de estágio e acompanhamento; dentre outras.

Para a denominada segunda etapa, uma vez já inseridos, o objetivo se torna a permanência no campo e as intervenções necessárias para garantia do direito ao desenvolvimento do estágio com qualidade. Cabe pensarmos como a articulação com as instituições contribui para oferecer melhores condições no processo de estágio, somadas ao atendimento de estudantes e à permanência dos professores nas disciplinas de supervisão. Ou seja, ações que visem o fortalecimento de vínculo institucional, da qualificação profissional e dos espaços de supervisão.

Como atribuição da gestão e do supervisor acadêmico, o contato permanente com o campo se faz como uma forma de acompanhamento a realização do estágio em seus diferentes aspectos, as condições de trabalho profissional e, consequentemente, da supervisão direta, mas também abre o diálogo a respeito da 
necessidade de tempo para qualificação. Uma vez que, como regulamenta a Resolução CFESS № 533, dentre as condições adequadas no campo, há requisitos básicos:

\begin{abstract}
Parágrafo único. Para sua realização, a instituição campo de estágio deve assegurar os seguintes requisitos básicos: espaço físico adequado, sigilo profissional, equipamentos necessários, disponibilidade do supervisor de campo para acompanhamento presencial da atividade de aprendizagem, dentre outros requisitos, nos termos da Resolução CFESS no 493/2006, que dispõe sobre as "condições éticas e técnicas do exercício profissional do assistente social" (CFESS, 2008).
\end{abstract}

O contato permanente com assistente social de campo, a oferta de atividades para qualificação, com ênfase na supervisão de estágio, são ações estratégicas. Sendo o profissional que, por meio do acompanhamento do estagiário, será capaz de apresentar a política setorial, o trabalho desenvolvido no espaço sócioocupacional e as condições técnicas, políticas e éticas, realizando reflexões críticas a respeito das potencialidades e limites da atuação. Se faz necessário pensar as ações do campo com as atividades propostas pela supervisora acadêmica e a garantia de eventos e espaços de debate a respeito do trabalho profissional, como as sugestões elencadas na primeira etapa, e a capacitação continuada.

Dentre as atividades a serem realizadas, em articulação com o supervisor de campo, pode-se promover com a Comissão de Estágio oficinas, cursos e fóruns, em caráter permanente, participação de convidados externos como palestrantes e/ou ouvintes nas disciplinas de supervisão e outras. Podemos somar ao acompanhamento contínuo e avaliação do estágio na UFA, como forma de garantir "a operacionalização de uma política de estágio condizente com os critérios e objetivos da formação profissional, com a participação de docentes, discentes e supervisores de campo" (ABEPSS, 2010, p. 24); toda a organização da documentação referente - desde a criação de modelos até a conferência e arquivamento dos mesmos, possibilitando o registro do aproveitamento do estudante dos respectivos vínculos. Como destaca Caputi (2016, p.392),

Supervisão de campo e acadêmica enquanto faces de uma mesma atividade curricular, dialeticamente demandam, por 
exemplo, respostas e reflexões próprias do arcabouço teóricoprático que constituem formação e trabalho profissional. Cujas respostas estão nas mediações construídas conjuntamente pelos seus atores: supervisores e estagiários no processo da supervisão, no espaço do fazer profissional, na análise institucional que se faz do trabalho profissional. Ambas as supervisões (de campo e acadêmica), tem suas particularidades. São momentos distintos que constituem intrinsecamente o mesmo processo, que é 0 estágio supervisionado. Logo, ambos/as supervisores/as devem dialogar e identificar as particularidades de suas respectivas proposições.

Cabe também buscar, no Estágio, a efetivação do princípio defendido na PNE (ABEPSS, 2010, p. 14), da articulação entre ensino, pesquisa e extensão, na realização da relação entre universidade e os diversos espaços de intervenção profissional, uma perspectiva de totalidade. E, no Fórum de Supervisão, uma estratégia política de fortalecimento e permanência do debate sobre a temática e vínculos entre docentes, profissionais e estudantes, bem como a garantia de construção de alternativas comuns à qualificação do estágio em Serviço Social.

O supervisor acadêmico, ao conduzir a disciplina de Estágio, tendo em vista o desenvolvimento das dimensões constitutivas da profissão (teórico-metodológica, ético-política e técnico-operativa) e canais de comunicação com supervisor de campo - via contato constante por e-mail, telefone, visitas institucionais -, para acompanhamento dos estudantes, realiza a participação no processo de supervisão. Nesse movimento, de aproximação junto à assistente social de campo, e com a troca realizada em sala, na produção de documentos (Plano de Estágio, Diários de Campo, Relatórios de Avaliação, etc.) com os estudantes, consegue vislumbrar as condições de trabalho profissional e o desempenho no estágio.

Por isso, ressaltamos que a discussão das questões referentes ao estágio troca de informações e experiências, a busca de unidade no encaminhamento dos conteúdos, articulação do processo de estágio com a proposta curricular e o acompanhamento do estudante no campo, o debate sobre o limite quantitativo de estudantes nas turmas (até 15), a garantia de disciplina para estágio não-obrigatório, a permanência dos professores na supervisão acadêmica, são aspectos a serem 
realizado com Coordenação de Curso e Departamento, no intuito de defesa da qualidade da formação.

Uma atividade que abarca essa demanda, e que tem sido regularmente realizada na ESS/UFF - Niterói, é a realização de encontros periódicos entre Coordenação e supervisores acadêmicos, para a elaboração de um cronograma de reuniões de acompanhamento de estudantes, exposição de dificuldades enfrentadas, organização de visitas aos campos, preparação de eventos, etc. Essa ação pode ser fortalecida com a participação de novos sujeitos, como docentes das disciplinas de Técnicas Interventivas, por exemplo.

Destacamos como uma importante ação, para o acompanhamento de estudantes, o atendimento social, juntamente com a necessidade de pensar a criação e manutenção de uma rede de serviços que atenda às demandas e fortaleçam o acesso aos direitos em busca de melhores condições de realização e permanência. Como aponta Brant Carvalho (2012, p.46), a gestão pública, na formulação e implementação de políticas sociais, deve inovar arranjos com "políticas e programas desenhados pelo prisma da intersetorialidade, reduzindo a ênfase nos tradicionais recortes setoriais e especializações estanques".

O que traz o entendimento de que a Coordenação de Estágio não deve restringir a atuação por meio de ações pontuais para o desenvolvimento do estágio, mas reconhecer a necessidade de contribuir de forma consistente na ampliação do acesso de estudantes a outras políticas sociais. Numa "gestão intersetorial capaz de integrar e re-totalizar a política social pública" (BRANT CARVALHO, 2012, p. 53), com respostas assertivas e combinadas na busca pelo direito a uma melhor qualidade de vida e condições de uma formação de qualidade.

\section{CONCLUSÃO}

Defende-se o estágio supervisionado em Serviço Social como central no processo de formação, sendo um lócus privilegiado de articulação das dimensões constitutivas da profissão. A partir dessa indissociabilidade do trabalho e formação profissional, faz-se fundamental o desenvolvimento de ações que visem contínua 
melhoria da experiência de estudantes no estágio, mas também contribuir com o processo de supervisão de assistentes sociais acadêmicos e de campo.

Os desafios estruturais, resultantes de uma sociedade desigual, e seu rebatimento direto na vida de estudantes e profissionais, trazem como exigência ações estratégicas que rompam com o fatalismo e messianismo. Desta forma, identifica-se grande potencialidade no trabalho da Coordenação de Estágio como um agente articulador dos sujeitos, tendo como horizonte a qualificação da formação em Serviço Social, em associação às ações para responder às demandas dos estudantes na realização do estágio e conclusão do curso.

Questiona-se, portanto, o motivo pelo qual, embora a orientação seja para a existência da instância da Coordenação de Estágio, ainda é frequente Unidades de Formação Acadêmica (UFAs) em que a Coordenação de Curso responde integralmente pelas questões relacionadas ao estágio. Esse fator implica no acompanhamento do desenvolvimento do estágio, a partir da aproximação contínua com os sujeitos envolvidos, bem como com as instituições que são espaços de atuação profissional do Serviço Social, somadas às atribuições e responsabilidades já existentes do curso. Entretanto, o que pode ser pensado, com relação a algumas instituições, é em certa desvalorização dos conteúdos teórico-práticos na formação, "até mesmo pela concepção de estágio e supervisão, ainda como secundários à formação e exercício profissional" (CAPUTI, 2016, p. 392), e a necessidade de avançarmos no debate e esforço pela contínua qualificação do estágio supervisionado em Serviço Social.

Assim, destacamos que as funções relativas à Coordenação de Estágio devem se centrar no estabelecimento de uma relação que proporcione a inserção de estudantes nos campos de estágio, acompanhando as ações desenvolvidas, a viabilidade de abertura e ampliação de vagas, sempre observando a qualidade do estágio e as condições vivenciadas pelos estagiários dentro e fora do campo. Também buscar fomentar a realização de atividades e fortalecimento da interação mais estreita entre os sujeitos envolvidos, com foco na capacitação dos supervisores de campo, relação que deve se dar respeitando os princípios da PNE (2010), bem como da política de estágio da UFA. 
Neste artigo, compartilhamos parte das reflexões que tem se desenhado a partir da experiência prática na Coordenação de Estágio, expondo as contradições e os tensionamentos que atravessam os desafios que preenchem tal cotidiano. $O$ debate em torno das potencialidades desta parcela da construção do estágio supervisionado em Serviço Social embora implique no enriquecimento do conhecimento e, consequentemente da atuação, ainda é significativamente escasso. Portanto, trazemos aqui questionamentos que se perpassam entre relatos do que temos experimentado na realidade da UFA, mas que se somam à uma dimensão de planejamento que pode se desdobrar em sugestões indicativas para a ampliação da discussão acerca deste espaço tão significativo para a promoção de uma formação profissional sintonizada ao Projeto Ético-Político do Serviço Social.

Por fim, entendemos que as possibilidades de atividades de organização administrativa e pedagógica do estágio na UFA, que podem ser implementadas tendo em vista a articulação dos sujeitos, são diversas. Mas, é necessário compreender que o processo de ensino-aprendizagem no estágio supervisionado deve responder pelo imperativo de construir atividades acadêmicas que permitam aos discentes uma formação profissional crítica e propositiva, sem perder de vista a direção social estratégica da profissão. Tendo o incremento da capacidade investigativa no processo formativo de assistentes sociais, como conteúdo transversal das disciplinas e dos demais componentes curriculares, perpassando toda a formação de discentes, potencializando condições para uma intervenção competente e que capacite para atuação no movimento coletivo de transformação da realidade social.

\section{REFERÊNCIAS}

ABEPSS. Associação Brasileira de Ensino e Pesquisa em Serviço Social. Diretrizes gerais para o curso de Serviço Social. Rio de Janeiro: ABEPSS, 1996. Disponível em:

http://www.abepss.org.br/arquivos/textos/documento_201603311138166377210.pdf

Política Nacional de Estágio. 2010. Disponível em:

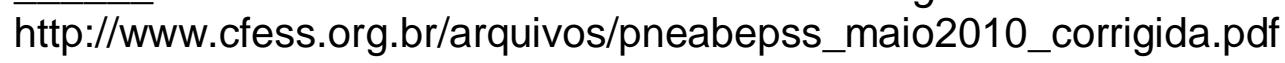


BRANT CARVALHO, Maria do Carmo. Gestão social e políticas públicas: uma questão ainda em debate no Século XXI. In: JUNQUEIRA, Luciano Antônio Prates [et al.] (orgs). Gestão Social Mobilizações e Conexões. São Paulo LCTE Editora, 2012.

BRASIL. Lei n. 8.662, de 7 de junho de 1993. Regulamentação da profissão de Assistente Social. Diário [da] República Federativa do Brasil, Brasília, DF, 8 jul. 1993.

CAPUTI, Lesliane. Supervisão de estágio em Serviço Social: significâncias e significados. In: R. Katál., Florianópolis, v. 19, n. 3, p. 389-394, out./dez. 2016

CONSELHO FEDERAL DE SERVIÇO SOCIAL (CFESS). Código de Ética Profissional dos Assistentes Sociais. Disponível em http://www.cfess.org.br/arquivos/CEP_CFESS-SITE.pdf Acesso: 14/08/2018.

Resolução CFESS n 533, de 29 de setembro de 2008. Regulamenta a SUPERVISÃO DIRETA DE ESTÁGIO no Serviço Social. Disponível em: http://www.cfess.org.br/arquivos/Resoluca0533.pdf

ESS/UFF. Política de Estágio. 2013

FERRI, Mônica Freitas. Estágio Supervisionado em Serviço Social: a indissociabilidade entre formação e trabalho profissional. In: Revista Temporalis, ABEPSS: v. 20 n. 39. Serviço Social e a Assistência Social: trajetórias e tendências. Brasília, 2020.

LEWGOY, Alzira Maria. Supervisão de Estágio em Serviço Social: desafios para a formação e exercício profissional. São Paulo: Cortez, 2010.

MARX, Karl; ENGELS, Friedrich. A ideologia Alemã. São Paulo: Expressão Popular, 2009

NETTO, José Paulo. A construção do projeto ético-político do Serviço Social. In: MOTA, Ana Elisabete; BRAVO, Maria Inês Souza; UCHÔA, Roberta et al. (Orgs.). Serviço social e saúde: formação e trabalho profissional. São Paulo: Cortez, 2006.

SILVA, Giselle; COIMBRA, Lenilse. Estágio Supervisionado em Serviço Social, determinantes estruturais e formação profissional: a experiência das assistentes sociais da coordenação e estágio da ESS/UFF no enfrentamento à evasão estudantil. 16ํㅡㄹ Congresso de Brasileiro de Assistentes Sociais. Distrito Federal/DF, 2019.

TEIXEIRA, Joaquina Barata. Formulação, administração e execução de políticas públicas. In: CFESS/ABEPSS. Serviço Social: direitos sociais e competências profissionais. Brasília, CFESS/ABEPSS/CEAD-UnB, 2009. 